\title{
Tingkat Kesetaraan Gender pada Rumah Tangga Petani Sawi di Pekon Campang Kecamatan Gisting Kabupaten Tanggamus
}

\author{
Indah Nurmayasari ${ }^{1}$, Abdul Mutolib ${ }^{2 *}$, Agus Hudoyo ${ }^{3}$ Amirul Khoirunnisa ${ }^{4}$, Ragil Ayu \\ Mangesti ${ }^{5}$, dan Risa Rahmadanti ${ }^{6}$ \\ 1,2,4,5,6 Program Studi Penyuluhan Pertanian, Fakultas Pertanian Universitas Lampung, Bandar \\ Lampung, Indonesia \\ ${ }^{3}$ Jurusan Agribisnis, Fakultas Pertanian Universitas Lampung, Bandar Lampung, Indonesia
}

Email:amutolib24@yahoo.com

\begin{abstract}
This study determine the role of women and the factors that influence gender equality in mustard vegetable farm households. The research method uses a quantitative approach with a survey method with research locations in Pekon Campang, Gisting District, Tanggamus Regency. The site selection was done purposively, with the consideration that the location was the center of vegetables in Tanggamus Regency. The number of respondents were 30 samples. The data used are primary data and secondary data. Data analysis uses the Harvard gender equality approach.The level of gender equality in mustard farmer households is measured through an activity profile approach which includes 1) the division of reproductive work, 2) the division of productive work, and 3) the division of social work and the profile of access and control of resources and benefits which include: 1) the level of equality in access to resources, 2) level of equality in access to benefits, 3) level of equality in control of resources, and 4) level of equality in control of benefits. The study was conducted in August to September 2019. The results of the study illustrate that in general women in mustard farmer families in Pekon Campang already have equality with men in domestic, farming, public / social activities with gender responsive classification. This can be seen from the participation of women in various activities both domestic, farming, and the public even though the Pekon Campang community adheres to a patriarchal culture but still pays attention to the role of women in various activities carried out both domestic, farming, and the public. Factors affecting gender equality in mustard farmer households include socio-cultural factors, beliefs, economic needs and community perceptions of the division of labor in the household and farming.
\end{abstract}

Keywords: gender, mustard farming, trust, patriarchy, and farm household

\begin{abstract}
Abstrak
Penelitian ini bertujuan untuk mengetahui peran perempuan dan faktor-faktor yang mempengaruhi kesetaraan genderdalam rumah tangga petani sawi. Metode penelitian menggunakan pendekatan kuantitatif dengan dengan metode survey dengan lokasi penelitian di Pekon Campang Kecamatan Gisting Kabupaten Tanggamus.Pemilihan lokasi dilakukan secara sengaja (purposive), dengan pertimbangan bahwa lokasi tersebut merupakan sentra sayuran di Kabupaten Tanggamus.Jumlah responden sebanyak 30 sampel. Data yang digunakan adalah data primer dan data sekunder. Analisis data menggunakan pendekatan kesetaraan gender model Harvard. Tingkat kesetaraan gender dalam rumah tangga petani sawi diukur melalui pendekatan profil aktifitas yang meliputi: 1) pembagian kerja reproduktif, 2) pembagian kerja produktif, dan 3) pembagian kerja sosial serta profil akses dan kontrol terhadap sumberdaya dan manfaat yang meliputi : tingkat kesetaraan dalam akses terhadap sumberdaya, tingkat kesetaraan dalam akses terhadap manfaat, tingkat kesetaraan dalam kontrol terhadap sumberdaya, dan tingkat kesetaraan dalam kontrol terhadap manfaat.Penelitian dilaksanakan pada bulan Agustus hingga September 2019. Hasil penelitian memberikan gambaran bahwasecara umum perempuan pada keluarga petani sawi di Pekon Campang telah memiliki kesetaraan dengan laki-laki dalam aktivitas domestik, usahatani,publik/sosial dengan klasifikasi responsif gender. Hal ini dapat dilihat dari partisipasi perempuan dalam berbagai kegiatan baik domestik, usahatani, dan publik meskipun masyarakat Pekon Campang menganut budaya patriarki tetapi tetap memperhatikan peran perempuan dalam berbagai kegiatan yang dilakukan baik yang bersifat domestik, usahatani, dan publik. Faktor-faktor yang memperngaruhi kesetaraan gender dalam rumah tangga petani sawi meliputi faktor sosial budaya, kepercayaan, kebutuhan ekonomi dan persepsi masyarakat terhadap pembagian kerja dalam rumah tangga dan usahatani.
\end{abstract}


Kata kunci :gender, usahatani sawi, kepercayaan, patriarki, dan rumah tangga

\section{Pendahuluan}

Perbedaan jenis kelamin berdasarkan budaya, di mana laki-laki dan perempuan dibedakan sesuai dengan perannya masing-masing yang dikonstruksikan oleh kultur setempat yang berkaitan dengan peran, sifat, kedudukan, dan posisi dalam masyarakat tersebut disebut dengan istilah gender (Rusni, 2015).Seks atau jenis kelamin merupakan perbedaan antara laki-laki dengan perempuan berdasarkan ciri biologisnya (Sudarman, 2008).Dalam banyak budaya tradisional khususnya dipedesaan, perempuan ditempatkan pada posisi yang dilirik setelah kelompok laki-laki (Mutolib, Yonariza, Mahdi dan Ismono, 2016).Fungsi dan peran yang diemban perempuan dalam mayarakat tersebut secara tidak sadar biasanya dikonstruksikan oleh budaya setempat sebagai warga negara kelas dua.Pada posisi inilah terjadi bias gender dalam masyarakat.Meski disadari bahwa ada perbedaan-perbedaan kodrati makhluk perempuan dan laki-laki secara jenis kelamin dan konstruksi tubuh, namun dalam konteks budaya peran yang diembannya haruslah memiliki kesetaraan.

Laki-laki dan perempuan memiliki peranan gender yang berbeda. Demikian juga pembagiaan peran dalam rumah tangga petani.Hasil penelitian Arkaniyati (2010) menunjukkan bahwa kegiatan usahatani merupakan kegiatan produktif yang melibatkan laki-laki dan perempuan dengan peranan yang bervariasi.Selain analisis peran gender, relasi antara laki-laki dan perempuan juga dapat dianalisis melalui perbedaan akses terhadap sumber daya.Tingkat akses sumber daya akan mempengaruhi kontrol dan manfaat serta partisipasi masing-masing pihak. Berbagai analisis relasi gender ini mengarah kepada tingkat keadilan dan kesetaraan gender pada berbagai tingkat masyarakat terutama pada tingkat terkecil yakni rumah tangga (Mutolib, Nikmatullah, Effendi, Viantimala, dan Rahmat, 2019).

Ketidaksetaraan gender dalam pertanian disebabkan banyak faktor seperti akses perempuan yang terbatas ke sumberdaya pertanian utama seperti tanah, tenaga kerja, pengetahuan, pupuk, dan benih sehingga berkontribusi kesenjangan antara laki-laki dan perempuan (FAO, 2011; Farnworth et al., 2016; Wambugu, Place, \& Franzel, 2011). Perempuan juga cenderung memiliki otoritas pengambilan keputusan yang lebih sedikit dan menghadapi hambatan sosial, budaya, dan kelembagaan tambahan untuk mengakses dan mengadopsi teknologi pertanian dalam upaya kesetaraan gender (Peterman et al., 2014; Peterman, Quisumbing, Behrman, \& Nkonya, 2011; Perez, Kristjanson, Förch, Thornton, \& Cramer, 2015; Listiana, Efendi,Mutolib, dan Rahmat, 2019).

Kabupaten Tanggamus merupakan sentra hortikultura di Provinsi Lampung. Pada tahun 2018, Kabupaten Tanggamus merupakan produsen hortikulturan dengan luasan tertinggi nomor dua di Provinsi Lampung untuk komoditas bawang merah, kubis dan petsai/sawi (BPS Provinsi Lampung, 2019). Sentra hortikultura terletak di Kecamatan Gisting yang berada di kaki Gunung Tanggamus yang memiliki udara sejuk sehingga cocok untuk tanaman hortikultura (BPS Tanggamus, 2019). Petsai/sawi merupakan salah satu komoditas hortikultura unggulan di Kecamatan Gisting, dari 26 jenis sayuran yang dihasilkan Petsai/sawi memiliki luas area 488 hektar dan terluas ketiga setelah Kubis (651 hektar) dan Bawang Merah (508 hektar) (BPS Tanggamus, 2019).

Topik mengenai analisis gender pada rumah tangga petani sudah pernah banyak diteliti seperti, Ratmayanti, Rahmadanih dan Salman (2018) tentang relasi gender pada rumah tangga petani cengkehdi Kabupaten Majene, Sulawesi Barat yang menyimpulkan bawa kaum laki-laki masih dominan dalam kegiatan produktif usahatani cengkeh. Angelie (2014) tentang peranan 
gender pada rumah tangga petani di Kabupaten BandungBarat, Jawa Baratyang menyimpulkan bahwa pembagian keputusan yang berkaitan dengan aktivitas reproduktif didominasi oleh perempuan dan laki-laki bersama perempuan, sedangkan pengambilan keputusan yang berkaitan dengan aktivitas produktif didominasi oleh laki-laki.Putri (2010) tentang relasi gender pada rumah tangga petani sayuran dataran rendah, menyimpulkan bahwa relasi gender pada rumah tangga petani sayur dipengaruhi oleh tiga faktor yaitu karakteritik pribadi petani, aksesibilitas informasi dan lingkungan. Pada usahatani padi sawah, Yunus, Salman, Demmallino, dan Viantika (2016), menemukan bahwa telah terjadi perubahan kelembagaan pada berbagai tahapan kerja yang salah satu efeknya adalah terpinggirkannya peran perempuan dalam usahatani padi sawah.

Penelitian tentang kesetaraan gender pada usahatani berbasis tanaman telah dilakukan, akan tetapi sifatnya masih umum dan belum spesifik komoditas seperti petsai/sawi. Penelitian ini akan mengkaji tingkat kesetaraan gender dalam usahatani sayuran secara spesifik komoditas yang bertujuan untuk memperluas pengetahuan terkait kesetaraan gender pada banyak komoditas khususnya sayuran. Penelitian ini bertujuan untuk mengetahui tingkat kesetaraan dan faktorfaktor yang mempengaruhi kesetaraan genderdalam rumah tangga petani sawidi Kecamatan Gisting Kabupaten Tanggamus.

\section{Metodologi}

\subsection{Lokasi dan Waktu Penelitian}

Penelitian dilakukan di PekonCampang, Kecamatan Gisting, Kabupaten Tanggamus.Gisting adalah sebuah Kecamatan di Kabupaten Tanggamus, Provinsi Lampung.Gisting merupakan destinasi wisata Kabupaten Tanggamus.Gisting berada di ketinggian \pm 700 mdpl dengan suhu udara sekitar $18-28{ }^{\circ} \mathrm{C}$, dan berada pada kaki Gunung Tanggamus.Gisting merupakan sentra pertanian seperti sayur mayur, seperti kubis, kentang dan wortel.Gisting memiliki pasar, rumah sakit, hotel dan beberapa lokasi wisata keluarga (Asiah, Yarmaidi dan Sugiyatna, 2019).Penelitian dilaksanakan pada bulan Agustus hingga September 2019.

\subsection{Jenis data dan Pendekatan Penelitian}

Data yang digunakan adalah data primer dan data sekunder. Data primer yaitu data diperoleh dari narasumber secara langsung menggunakan metode wawancara. Data sekunder diperoleh melalui laporan dari buku, jurnal, dinas dan instansi terkait. Metode penelitian menggunakan pendekatan kuantitatif dengan dengan metode survey.Jumlah responden sebanyak 30 sampel. Tahapan penelitian yang dilakukan adalah tahap invention (tahap pra-lapangan yang berisi menyusun, memilih lokasi, serta memilih narasumber penelitian), tahap discovery (tahap pelaksanaan pengambilan data di lapangan), dan tahap explanation (tahap pengolahan data, mengorganisir, dan mendeskripsikan data yang diperoleh) (Anggito dan Setiawan, 2018).

\subsection{Analisis data}

Data dianalisis menggunakan analisis tabulasi silang atau Crosstabs untuk menghitung frekuensi dan persentase dua atau lebih variabel secara sekaligus dengan cara menyilangkan variabel-variabel yang dianggap berhubungan sehingga makna hungan dua variabel dapat mudah dipahami secara deskriptif (Sarwono 2009, Putri, Ashari Wibawa dan Persada 2017).Kerangka penelitian menggunakan pendekatan analisis harvard denganmengumpulkan data skala mikro atau skala rumah tangga dan masyarakat. Kerangka ini terdiri atas tiga elemen pokok, yaitu profil aktivitas, profil akses dan kontrol terhadap sumberdaya dan manfaat, dan faktor yang mempengaruhi (March et al.1999).

a) Profil aktivitas, dalam profil aktivitas dikelompokkan menjadi peran produktif, reproduktif dan sosial. Peran gender adalah peran yang diciptakan masyarakat bagi perempuan dan laki- 
laki. Dalam bentuk ideal peran adalah suatu kombinasi dari peran yang dirumuskan dan peran yang diharapkan ditambah dengan peran yang diterima (Hubeis 2010).

b) Profil akses dan kontrol terhadap sumberdaya dan manfaat, dalam profil akses merujuk pada kesempatan untuk menggunakan sumber daya produktif dan manfaat yang didapatnya tanpa memiliki wewenang untuk mengambil keputusan terhadap cara penggunaan dan hasil sumber daya tersebut dalam program. Sementara itu, profil kontrol merujuk pada kewenangan untuk mengambil keputusan atas penggunaandan hasil sumber daya dan manfaat yang telah didapat. Individu yang mencapai tingkat kontrol dapat membuat keputusan mengenai penggunaan sumberdaya dan apapun yang bisa dijualnya (March et al. 1999).

c) Faktor-faktor yang mempengaruhi, elemen ini adalah mengurutkan faktor-faktor yang memberikan pengaruh terhadap perbedaan gender dalam pembagian kerja, akses dan kontrol terhadap sumberdaya dan manfaat. Faktor-faktor yang mempengaruhi, termasuk relasi gender, norma komunitas, kepercayaan, budaya, kondisi demografi, struktur institusional, kondisi ekonomi dan faktor internal dan eksternal politik (March et al. 1999).

\section{Hasil dan Pembahasan}

\subsection{Gambaran Umum Responden}

Rata-rata usia responden adalah 40-47 tahun, dengan rincian rentang usia 40-47 tahun sebanyak 13 responden, 48-55 tahun sebanyak 10 responden, dan 56-62 tahun sebanyak 7 responden. Responden yang diwawancarai berjenis kelamin laki-laki sebanyak 27 responden dan perempuan sebanyak 3 (tiga) responden. Keseluruhan responden bersuku Jawa. Pendidikan responden didominasi lulusan SMA sebanyak 18 responden, 9 (sembilan) responden berpendidikan SMP dan 3 (tiga) responden lulusan SD. Pendidikan erat kaitannya dengan kemampuan petani dalam menerima ilmu dan inovasi baru (Hamid, Nurtanto, Rahmat, Mutolib, Nurhaji, Fawaid, dan Rizal, 2018; Yanfika, Listiana, Mutolib, dan Rahmat, 2019). Lama mukim responden antara 47 hingga 60 tahun sebanyak 15 responden, lama mukim 19-32 tahun sebanyak 9 responden, dan lama mukim 33-46 tahun sebanyak 6 responden. Lama berusa hatani sawi berkisar antara 2 hingga 11 tahun sebanyak 12 responden, 12 sampai 21 tahun sebanyak 12 responden, dan 22 hingga 31 tahun sebanyak 6 (enam) responden.

\subsection{Profil Aktivitas}

1. Pembagian Kerja Reproduktif

Profil aktivitas difokuskan pembagian jam kerja yang dilakukan laki laki dan perempuan dalam melakukan usahatani sayuran (Bhastoni,2016). Pembagian kerja reproduktif pada petani sawi di Pekon Campang terbagi dalam tiga kategori yaitu perspektif gender, bias gender dan responsif gender. Pembagian kerja reproduktif petani sawi di Pekon Campang ditampilkan dalam Tabel 1.

Tabel 1.Pembagian kerja reproduktif pada rumah tangga petani sawi di Pekon Campang Kecamatan Gisting Kabupaten Tanggamus

\begin{tabular}{lccc}
\hline \multicolumn{1}{c}{ Persepsi Gender } & \multicolumn{3}{c}{ Pembagian Kerja Reproduktif (\%) } \\
\cline { 2 - 4 } & $\begin{array}{c}\text { L/P } \\
\text { (Bias gender) }\end{array}$ & $\begin{array}{c}\text { BDL/BDP } \\
\text { (Perspektif gender) }\end{array}$ & $\begin{array}{c}\text { B } \\
\text { (Responsif gender) }\end{array}$ \\
\hline Rendah $(0-33,33 \%)$ & 0,00 & 0,00 & 16,25 \\
Sedang $(33,34-66,67 \%)$ & 40,00 & 40,14 & 0,00 \\
Tinggi $(66,68-100 \%)$ & 0,00 & 0,00 & 0,00 \\
\hline
\end{tabular}

Sumber: Data primer, 2019

Berdasarkan Tabel 1 dapat diketahui bahwa pembagian kerja reproduktif bersifat perspektif gender sebanyak 40,14 persen (kontrol manfaat dilakukan secara bersama dominan laki-laki dan 
bersama dominan perempuan) yang mana perempuan terlibat dalam kegiatan usahatani sawi,berperan aktif dalam pengelola serta memberikan kontribusi secara ekonomi bagi pendapatan keluarga. Temuan ini memberikan gambaran bahwa kegiatan usaha tani yang mulanya dominan dilakukan oleh kepala rumah tangga mulai bergeser ke anggota keluarga dalam hal ini perempuan (Syarif,2017). Sebanyak 40 persen menjelaskan bahwa pembagian keja reproduktif bersifat bias gender (kegiaan kerja reproduktif hanya dilakukan oleh laki-laki atau perempuan saja). Sedangkan 16,25 persen pembagian keja reproduktif bersifat responsif gender (kegiatan kerja reproduktif dilakukan secara bersama sama anatara laki-laki dan perempuan secara adil). Secara umum tingkat kesetaraan gender rumah tangga petani sawi di Pekon Campangrendah, hal ini terlihat dari rendahnya tingkat responsif gender dalam pembagian kerja produktif pada petani sawi di Pekon Campang.

2. Pembagian Kerja Produktif

Pembagian kerja produktif berkaitan dengan pekerjaan yang berkaitan dengan usahatani yang menjadi sumber utama mata pencaharian meliputi persiapan lahan, penanaman, pemeliharaan, pemanenan, pengangkutan dan lain sebagainya. Pembagian kerja produktif petani sawi di Pekon Campang ditampilkan dalam Tabel 2.

Tabel 2. Pembagian kerja produktif pada rumah tangga petani sawi di Pekon Campang Kecamatan Gisting

\begin{tabular}{lccc} 
& \multicolumn{2}{c}{ Kabupaten Tanggamus } \\
\hline \multirow{2}{*}{ Persepsi Gender } & \multicolumn{3}{c}{ Pembagian Kerja Produktif (\%) } \\
& $\begin{array}{c}\text { L/P } \\
\text { (Bias gender) }\end{array}$ & $\begin{array}{c}\text { BDL/BDP } \\
\text { (Perspektif gender) }\end{array}$ & $\begin{array}{c}\text { B } \\
\text { (Responsif gender) }\end{array}$ \\
\hline Rendah (0-33,33\%) & 0,00 & 25,00 & 0,00 \\
Sedang (33,34-66,67 \%) & 36,00 & 0,00 & 39,00 \\
Tinggi (66,68-100 \%) & 0,00 & 0,00 & 0,00 \\
\hline Sumber: Data primer, 2019 & & &
\end{tabular}

Melalui Tabel 2 diketahui bahwa sebanyak 36 persen pembagian kerja produktif bersifat bias gender. Sebesar 25 persen pembagian keja produktif bersifat perspektif gender yang mana kegiatan kerja reproduktif dilakukan secara bersama dominan laki-laki dan bersama dominan perempuan, dan sebesar 39 persen petani sawi menerapkan pembagian keja produktif bersifat responsif gender. Tingginya persentase responsif gender dipengaruhi oleh adanya kepercayaan laki-laki terhadap perempuan dalam melakukan produksi, serta dipengaruhi kondisi ekonomi yang mengharuskan laki-laki melibatkan perempuan dalam kegiatan produksi.

3. Pembagian Kerja Sosial

Pembagian kerja sosial berkaitan dengan aktivitas sosial rumah tangga petani. Aktivitas sosial yang dikaji untuk melihat kesetaraan gender dalam pembagian kerja sosial meliputi: 1) arisan, rapat kelompok tani, penyuluhan pertanian, hajatan, pengajian, dan rembuk desa. Pembagian kerja sosial rumah tangga petani sawi di Pekon Campang ditampilkan dalam Tabel 3.

Tabel 3. Pembagian kerja sosial pada rumah tangga petani sawi di Pekon Campang Kecamatan Gisting Kabupaten

\begin{tabular}{lccc}
\multicolumn{3}{c}{ Tanggamus } \\
\cline { 2 - 4 } Persepsi Gender & \multicolumn{3}{c}{ Pembagian Kerja Sosial (\%) } \\
& $\begin{array}{c}\text { L/P } \\
\text { (Bias gender) }\end{array}$ & $\begin{array}{c}\text { BDL/BDP } \\
\text { (Perspektif gender) }\end{array}$ & $\begin{array}{c}\text { B } \\
\text { (Responsif gender) }\end{array}$ \\
\hline Rendah $(0-33,33 \%)$ & 0,00 & 23,33 & 20,00 \\
Sedang $(33,34-66,67 \%)$ & 56,67 & 0,00 & 0,00 \\
Tinggi $(66,68-100 \%)$ & 0,00 & 0,00 & 0,00 \\
\hline
\end{tabular}

Sumber: Data primer, 2019 
Sebesar 56,67 persen pembagian kerja sosial pada tangga petani sawi bersifat bias gender (kegiaan kerja sosial hanya dilakukan oleh laki-laki atau perempuan saja). Sebesar 23,33 persen pembagian keja sosial bersifat perspektif gender dan sebesar 20 persen pembagian keja sosialbersifat responsif gender. Secara umum, petani sawi di Pekon Campang besar belum menerapkan prinsip keadilan gender dalam pembagian kerja sosial.

\subsection{Profil Akses dan Kontrol terhadap Sumberdaya dan Manfaat}

Profil akses dan kontrol terhadap sumberdaya dan manfaatmerujuk pada kesempatan untuk menggunakan sumber daya produktif dan manfaat yang didapatnya tanpa memiliki wewenang untuk mengambil keputusan terhadap cara penggunaan dan hasil sumber daya tersebut dalam program. Sementara itu, profil kontrol merujuk pada kewenangan untuk mengambil keputusan atas penggunaandan hasil sumber daya dan manfaat yang telah didapat (March et al.1999).

1. Tingkat Kesetaraan dalam Akses Terhadap Sumberdaya

Tingkat kesetaraan dalam akses terhadap sumberdaya meliputi keterlibatan dan peranan perempuan dalam mengakses sumberdaya dalam rumah tangga terutama pada kegiatan yang mendukung aspek kerja produktif seperti membantu membeli peralatan, mengakses terhadap lahan, dan terlibat dalam proses jual beli hasil sayuran. Tingkat kesetaraan dalam akses terhadap sumberdaya pada rumah tangga petani sawi di Pekon Campang ditampilkan dalam Tabel 4.

Tabel 4. Tingkat kesetaraan dalam akses terhadap sumberdaya dalam rumah tangga petani sawi di Pekon Campang Kecamatan Gisting Kabupaten Tanggamus

\begin{tabular}{cccc}
\hline & \multicolumn{2}{c}{ Tingkat Kesetaraan dalam Akses Terhadap Sumberdaya (\%) } \\
\cline { 2 - 3 } Persepsi Gender & $\begin{array}{c}\text { L/P } \\
\text { (Bias gender) }\end{array}$ & $\begin{array}{c}\text { BDL/BDP } \\
\text { (Perspektif gender) }\end{array}$ & $\begin{array}{c}\text { B } \\
\text { (Responsif gender) }\end{array}$ \\
\hline Rendah $(0-33,33 \%)$ & 0,00 & 0,00 & 22,50 \\
Sedang $(33,34-66,67 \%)$ & 42,50 & 35,00 & 0,00 \\
Tinggi $(66,68-100 \%)$ & 0,00 & 0,00 & 0,00 \\
\hline
\end{tabular}

Sumber: Data primer, 2019

Sebesar 42,50 persen rumah tangga petani sawi menerapkan kesetaraan dalam akses terhadap sumberdaya yang bersifat bias gender.Sebesar 35 persen peran kesetaraan dalam akses terhadap sumberdaya bersifat perspektif gender.Sebesar 22,50 persen akses terhadap sumberdaya bersifat responsif gender. Tingginya persentase bias gender pada rumah tangga petani sawi dipengaruhi oleh adanya pengaruh budaya yang membangun stereotipe bahwa pekerjaan dilahan pertanian adalah milik para laki-laki, sehingga akses perempuan dalam sumberdaya menjadi terbatas dibandigkan laki-laki.

2. Tingkat kesetaraan dalam akses terhadap manfaat

Tingkat kesetaraan gender dalam akses terhadap manfaat meliputi tingkat kesetaraan antara laki-laki dengan perempuan dalam memanfaatkan hasil penjualan sayuran, memanfaatkan penghasilan untuk kebutuhan pangan dan rumah tangga, mengakses manfaat politik desa dan lain sebagainya. Tingkat kesetaraan dalam akses terhadap manfaat pada rumah tangga petani sawi di Pekon Campang ditampilkan dalam Tabel 5.

Tabel 5.Tingkat kesetaraan dalam akses terhadap manfaat pada rumah tangga petani sawi di Pekon Campang Kecamatan Gisting Kabupaten Tanggamus

\begin{tabular}{lccc}
\hline \multirow{2}{*}{ Persepsi Gender } & \multicolumn{2}{c}{ Tingkat Kesetaraan dalam Akses Terhadap Manfaat (\%) } \\
\cline { 2 - 4 } & $\begin{array}{c}\text { L/P } \\
\text { (Bias gender) }\end{array}$ & $\begin{array}{c}\text { BDL/BDP } \\
\text { (Perspektif gender) }\end{array}$ & $\begin{array}{c}\text { B } \\
\text { (Responsif gender) }\end{array}$ \\
\hline Rendah $(0-33,33 \%)$ & 21,67 & 31,66 & 0,00 \\
Sedang $(33,34-66,67 \%)$ & 0,00 & 0,00 & 40,00 \\
Tinggi $(66,68-100 \%)$ & 0,00 & 0,00 & 0,00 \\
\hline
\end{tabular}

Sumber: Data primer, 2019 
Dari Tabel 5 diperoleh gambaran bahwa tingkat kesetaraan terhadap akses manfaatpada rumah tangga petani sawi di Pekon Campang manfaat didominasi dengan kategori responsif gender dengan persentase 40 persen. Sebesar 21,67 persen kesetaraan dalam akses terhadap manfaat bersifat bias gender. Sedangkan tingkat kesetaraan terhadap akses manfaat yang bersifat perspektif gendr sebesar 31,66 persen. Tingginya persentase responsif gender dipengaruhi oleh adanya kepercayaan dari laki-laki terhadap perempuan dalam hal akses terhadap manfaatpengaruhi oleh adanya faktor budaya yang berkembang di Pekon Campang bahwa keuangan terutama untuk kebutuhan rumah tangga dan lain sebagainya dikelola oleh pihak perempuan.

3. Tingkat kesetaraan dalam kontrol terhadap sumberdaya

Tingkat kesetaraan dalam kontrol terhadap suberdaya meliputi tingkat kesetaraan antara laki-laki dengan perempuan dalam mengontrol sumberdaya diantaranya: 1) memutuskan menjual hasil usahatani, 2) memutuskan menjual aset, 3) memutuskan menanam komoditas/jenis tanaman tertentu, dan 4) memutuskan membeli perlatan ditampilkan dalam Tabel 6.

Tabel 6. Tingkat kesetaraan dalam kontrol terhadap sumberdaya pada rumah tangga petani sawi di Pekon Campang Kecamatan Gisting Kabupaten Tanggamus

\begin{tabular}{lccc}
\hline \multirow{2}{*}{ Persepsi Gender } & \multicolumn{2}{c}{ Tingkat Kesetaraan dalam Kontrol Terhadap Sumberdaya (\%) } \\
\cline { 2 - 4 } & $\begin{array}{c}\text { L/P } \\
\text { (Bias gender) }\end{array}$ & $\begin{array}{c}\text { BDL/BDP } \\
\text { (Perspektif gender) }\end{array}$ & $\begin{array}{c}\text { B } \\
\text { (Responsif gender) }\end{array}$ \\
\hline Rendah $(0-33,33 \%)$ & 32,00 & 30,00 & 0,00 \\
Sedang $(33,34-66,67 \%)$ & 0,00 & 0,00 & 38,00 \\
Tinggi $(66,68-100 \%)$ & 0,00 & 0,00 & 0,00 \\
\hline
\end{tabular}

Sumber: Data primer, 2019

Dari Tabel 6 diketahui bahwa tingkatkesetaraan gender dalam kontrol terhadap sumberdaya bersifat bias gender sebanyak 32 persen, sedangkan tingkatkontrol terhadap sumberdaya bersifat perspektif gender sebanyak 30 persen, serta sebanyak 38 persen kontrol terhadap sumberdaya bersifat responsif gender. Petani sawi di Pekon Campang cenderung menerapkan keputusankeputusan yang responsif gender karena dipengaruhi oleh kepercayaan dari laki-laki kepada perempuan serta dukungan budaya yang memberi ruang kepada perempuan dalam mengontrol sumberdaya.

4. Tingkat kesetaraan dalam kontrol terhadap manfaat

Tingkat kesetaraan dalam kontrol terhadap manfaat meliputi tingkat kesetaraan antara lakilaki dengan perempuan dalam mengontrol terhadap manfaat yang meliputi: 1) Mengatur alokasi manfaat, 2) Pemenuhan kebutuhan dasar, 3) Pemenuhan Pendidikan, dan 4) Mengelola pengeluaran ditampilkan dalam Tabel 7.

Tabel 7.Tingkat kesetaraan dalam kontrol terhadap manfaat pada rumah tangga manfaat petani sawi di Pekon Campang Kecamatan Gisting Kabupaten Tanggamus

\begin{tabular}{lccc}
\hline \multirow{2}{*}{ Persepsi Gender } & \multicolumn{2}{c}{ Tingkat Kesetaraan dalam Kontrol Terhadap Manfaat (\%) } \\
\cline { 2 - 4 } & $\begin{array}{c}\text { L/P } \\
\text { (Bias gender) }\end{array}$ & $\begin{array}{c}\text { BDL/BDP } \\
\text { (Perspektif gender) }\end{array}$ & $\begin{array}{c}\text { B } \\
\text { (Responsif gender) }\end{array}$ \\
\hline Rendah (0-33,33\%) & 6,00 & 0,00 & 0,00 \\
Sedang (33,34-66,67 \%) & 0,00 & 44,00 & 50,00 \\
Tinggi (66,68-100\%) & 0,00 & 0,00 & 0,00 \\
\hline Sumber: Data primer, 2019 & & &
\end{tabular}

Dari Tabel 7 diketahui bahwa sebesar 44 persen kontrol terhadap manfaat bersifat perspektif gender. Kemudian, sebesar 50 persen kontrol terhadap manfaat bersifat responsif gender. Petani sawi di Pekon Campang cenderung menerapkan keputusan-keputusan yang 
responsif gender, hal ini terlihat dari tingginya persentase terhadap responsif dalam kontrol terhadap manfaat. Tingginya angka responsif gender dalam kesetaraan dalam kontrol terhadap manfaat dalam rumah tangga petani dipengaruhi oleh kepercayaan dari laki-laki kepada perempuan serta dukungan budaya yang memberi ruang kepada perempuan dalam mengontrol sumberdaya.

\subsection{Faktor-Faktor yang Mempengaruhi Kesetaraan Gender}

Secara umum perempuan pada rumah tangga petani sawi di Pekon Campang telah memiliki kesetaraan dengan laki-laki dalam aktivitas domestik, usahatani,publik/sosial dengan klasifikasi responsif gender.Hal ini dapat dilihat dari partisipasi perempuan dalam berbagai kegiatan baik domestik, usahatani, dan sosial.Adanya saling kepercayaan antara laki-laki dan perempuan dalam melaksanakan kegiatan sehari-hari dan produktif serta lainnya menjadi salah satu faktor terbentuknya responsif gender.Selain itu, keterbatasan ekonomi rumah tangga petani sayuran sawi menuntut diperlukannya kerjasama antara laki-laki dan perempuan dalam mendukung kegiatan baik reproduktif maupun produktif.Peran perempuan mengalami pergeseran dan meluas tidak hanya pada bidang reproduktif saja, tetapi pada bidang produktif, sosial dan lain sebagainya.

Pergeseran pembagian kerja antara laki-laki dan perempuan membawa perubahan pada peranan laki-laki dan perempuan dalam keluarga dan rumah tangga(Sampurno,2008).Keterlibatan perempuan dalam mengelola pertanian pada rumah tangga petani sawi terdistribusi pada tiap-tiap kegiatan dimulai dalam penanaman hingga pemanenan diantarana keterlibatan perempuan dalam penyeleksian benih dan penyemaiansawi.Keterlibatan perempuan dalam semua aktivitasekonomipada rumah tangga petani sawi juga cukup tinggi dan semakin meluas. Meskipun demikian, dalam mengambil keputusan penting dalam rumah tangga petani sawi perempuan belum diberi kesempatan dan wewenang yang cukup besar. Temuan ini sejalan dengan penelitian Zainuddin (2017) yang menjelaskan bahwa peranan perempuan masih terbatas dalam rumah tangga petani belum pada kegiatan pembagian kerja produktif, sosial dan kegiatan lainnya.

\section{Kesimpulan}

Tingkat kesetaraan gender dalam penelitian ini diukur melalui pendekatan profil aktifitas dan profil akses-kontrol. Profil aktivitas meliputi deskripsi tentang pembagian kerja reproduktif, produktif,dan sosial. Profil akses dan kontrol meliputi deskripsi tingkat kesetaraan dalam akses terhadap sumberdaya, akses terhadap manfaat, kontrol terhadap sumberdaya, dan kontrol terhadap manfaat dalam rumah tangga. Hasil penelitian memberikan gambaran bahwa: 1) Profil aktifitas rumah tangga petani sawi di Pekon Campang didominasi kegiatan yang bersifat bias gender atau belum memberikan kesetaraan terhadap perempuan (meliputi pembagian kerja produktif dan pembagian kerja sosial), sedangkan pembagian kerja reproduktif bersifat perspektif genderyang mana kontrol manfaat dilakukan secara bersama antara laki-laki dan perempuan. Profil akses dan kontrol terhadap sumberdaya dan manfaat dalam rumah tangga secara umum sudah responsif gender atau perempuan memiliki tingkat kesetaraan tinggi dalam akses dan kontrol terhadap sumberdaya dan manfaat. 2) Faktor-faktor yang memperngaruhi kesetaraan gender dalam usahatani sawi di Pekon Campang Kecamatan Gisting Kabupaten Tanggamus meliputi faktor sosial budaya, kepercayaan, kebutuhan ekonomi dan persepsi masyarakat terhadap pembagian kerja dalam rumah tangga dan usahatani. 


\section{Saran}

Perempuan memiliki peranan yang masih rendah dalam rumah tangga petani sawi di Pekon Campang Kecamatan Kabupaten Tanggamus Provinsi Lampung. Melalui analisis profil aktivitas dan profil akes-kontrol diperoleh gambaran bahwa peran perempuan hanya dominan pada kegiatan reproduktif yang berkaitan dengan kegiatan rumah tangga seperti memasak, mengurus rumah, memandikan anak dan sebagainya. Kegiatan-kegiatan lain seperti manajemen usahatani serta akses dan kontrol terhadap sumberdaya keluarga masih didominasi kaum laki-laki. Salah faktor yang mempengaruhi ketidaksetaraan gender adalah kurangnya kesempatan kaum perempuan untuk tampil dalam kegiatan sosial kemasyarakatan, hal ini menimbulkan anggapan umum (stereotype) dalam masyarakat bahwa kaum laki-laki memiliki kemampuan diatas perempuan atau sulit bagi perempuan untuk dapat sejajar dengan laki-laki. Oleh karena itu, perlunya membangun suatu wadah (organisasi) yang dapat meningkatkan partisipasi dan kepercayaan diri perempuan agar dapat meghilangkan stereotype tehadap ketidakmampuan/ ketidakberdayaan perempuan. Salah satu upaya yang dapat ditempuh adalah membentuk Kelompok Wanita Tani disetiap Pekon/Dusun untuk meningkatkan kesadaran dan partisipasi perempuan tani untuk berorganisasi dan berkontribusi bagi masyarakat.

\section{Daftar Pustaka}

Angelie, L. 2014. Peranan gender pada rumah tangga petani di Desa Sunten Jaya, Kecamatan Lembang, Kabupaten Bandung Barat, [Skripsi]. Bogor: Institut Pertanian Bogor.

Anggito, A. dan Setiawan, J. 2018.Metodologi Penelitian Kualitatif. Sukabumi: CV Jejak.

Ashari, BH., Wibawa,BM., Persada, SF. 2017. Analisis Deskriptif dan Tabulasi Silang pada Konsumen Online shop di Instagram (Studi Kasus 6 Universitas di Kota Surabaya). Jurnal Sains dan Seni ITS. 6(1): 17-21.

Asiah, S.N., Yarmaidi., dan I.G. Sugiyanta. 2019.Analisis Potensi Longsor Kecamatan Gisting Kabupaten Tanggamus Tahun 2018. Jurnal penelitian Fakultas Keguruan.

Bhastoni, K., Y. Yuliati. 2016. Peran Wanita Tani diatas Usia Produktif dalam Usahatani Sayuran Organik Terhadap Pendapatan Rumah Tangga di Desa Sumberrejo Kecamatan Batu. Habitat,26(2):119-129.

BPS Kabupaten Tanggamus. 2019. Kabupaten Tanggamus Dalam Angka 2019. Kota Agung: Badan Pusat Statistik.

BPS Kabupaten Tanggamus. 2019. Kecamatan Gisting Dalam Angka 2019. Kota Agung: Badan Pusat Statistik.

BPS Provinsi Lampung. 2019. Provinsi Lampung Dalam Angka 2019. Bandar Lampung: Badan Pusat Statistik.

FAO. (2011). The state of food and agriculture 2010-11.women in agriculture: Closing the gender Gap for development. Rome

Farnworth, C. $\quad$ R., Baudron, F., Andersson, J. $\quad$ A., Misiko, M., Badstue, L., $\quad$ \& Stirling, C. M. 2016. Gender and conservation agriculture in east and Southern Africa: Towards a research agenda. International Journal of Agricultural Sustainability, 14(2), 142-165. doi: 10.1080/14735903.2015.1065602

Hamid, MA.,Nurtanto, M., Rahmat, A., Mutolib, A., Nurhaji, S., Fawaid, M., dan Rizal, SU. 2018. The Analysis of Learning Implementation Plan (LIP) in Vocational Subjects Based on 2013 Curriculum.Advances in Social Science, Education and Humanities Research (ASSEHR), volume 161

Hubies, AVS. 2010.Pemberdayaan Perempuan dari Masa ke Masa.Bogor: IPB Press.

Listiana, I. Efendi, I. Mutolib, A. dan Rahmat, A. 2019. The behavior of Extension Agents in 
Utilizing Information and Technology to Improve the Performance of Extension Agents in Lampung Province.Journal of Physics: Conference Series, 1155(012004): 1-9.

March, Candida et al. 1999.A Guide to Gender-Analysis Framework. Oxford: An Oxfam Publication.

Mutolib, A., Nikmatullah, D., Effendi, I. Viantimala, B., dan Rahmat, A. 2019. Kontribusi Dana Desa dalam Pembangunan Badan Usaha Milik Desa di Desa Hanura, Kabupaten Pesawaran, Provinsi Lampung.JSHP: Jurnal Sosial Humaniora dan Pendidikan, 3(1): 1019.

Mutolib, A., Yonariza, Mahdi, \& Ismono, H. 2016. Gender inequality and the oppression of women within minangkabau matrilineal society: A Case study of the management of ulayat forest land in nagari bonjol, dharmasraya district, west sumatra province, Indonesia. Asian Women, 32(3), 23-49.

Perez, C., Kristjanson, P., Förch, W., Thornton, P. K., \& Cramer, L. 2015. How resilient are farming households, communities, men and women to a changing climate in Africa? Global Environmental Change, 34, 95-107. doi: 10.1016/j.gloenvcha.2015.06.003

Peterman, A., Behrman, J. A., Quisumbing, A. R., et al. 2014. A review of empirical evidence on gender differences in nonland agricultural inputs, technology, and services in developing countries. In A. R. Quisumbing (Ed.), Gender in agriculture: Closing the knowledge Gap (pp. 145-186). Dordrecht: Springer.

Peterman, A., Quisumbing, A., Behrman, J., \& Nkonya, E. 2011. Understanding the complexities surrounding gender differences in agricultural productivity in Nigeria and Uganda. Journal of Development Studies, 47(10), 1482-1509. doi: 10.1080/00220388.2010.536222

Putri, Sinta Rahmi. 2010. Relasi gender pada rumah tangga petani sayur dataran rendah. [Skripsi]. Bogor: Institut Pertanian Bogor.

Ratmayani, Rahmadanih, D. Salman, 2018. Relasi Gender pada Rumah Tangga Petani Cengkeh, JSEP 14(1): 65 - 74.

Rusni, Syaribulan, dan Nurdin. 2015. Geneologi Gender pada Perempuan Pembuat Ikan Kering.Jurnal Equilibrium Pendidikan Sosiologi,3(1).

Sampurno. 2008. Pembagian Kerja Antara Laki-Laki dan Perempuan di Dusun Sambirejo Desa Seloharjo Kec. Pundong Kab.Bantul. Skripsi.Universitas Negeri Islam Sunan Kalijaga.Yogyakarta.

Sarwono, J. 2009. Statistik Itu Mudah: Panduan Lengkap untuk Belajar Komputasi Statistik Menggunakan SPSS 16. Yogyakarta: Andi Offset.

Sudarma, M. 2008. Sosiologi Untuk Kesehatan. Salemba Medika. Jakarta.

Syarif, A., M. Zainuddin. 2017. Kontribusi Ekonomi dan Peran Perempuan dalam pengambilan Keputusan pada Usahatani Sayuran di Kabupaten Bantaeng.Prosiding seminar hasil penelitian.Diakses pada tanggal 26 November 2019 pukul 20.15 WIB.

Wambugu, C., Place, F., \& Franzel, S. 2011. Research, development and scaling-up the adoption of fodder shrub innovations in east Africa. International Journal of Agricultural Sustainability, 9(1), 100-109. doi: 10.3763/ijas.2010.0562

Yanfika, H. Listiana, I. Mutolib,A. dan Rahmat, A. 2019. Linkages between Extension Institutions and Stakeholders in the Development of Sustainable Fisheries in Lampung Province.Journal of Physics: Conference Series, 1155 (01201): 1-9.

Yunus, A., D. Salman, Demmallino, E.B., Viantika, N.M., 2016.Sociotechnical Change and Institutional Adjustment in Paddy Rice Farming During Post Green Revolution in Indonesia. IJAS, Vol.2, Issue 2. 